\title{
The Red Cross will be one hundred years old this year
}

On June 24, 1859, 30 to 40,000 wounded lay uncared for on the battle-field of Solferino at the mercy of the heat, looters and birds of prey. Henry Dunant was an accidental witness of this disaster and he was so shocked by the suffering and so scandalized by the inadequacy of the medical services that he improvised a relief action with the help of some local country women.

The memory of the aftermath of this battle tortured him for 3 years and in 1862, he published $A$ Memory of Solferino. This book aroused considerable interest, and the Public Welfare Society of Geneva studied the suggestions made by the author at the end of his book: Would it not be possible in time of peace to form relief societies? And could not governments conclude an international treaty which would form a basis for the work of these societies?

On February 17, 1863, the four commissioners charged with this study, General Dufour, Gustave Moynier, Dr. Appia and Dr. Maunair, gave the first practical effect to these suggestions by setting themselves up, together with Dunant, as the Permanent International Committee for Relief to Military Wounded, which was to become the International Committee of the Red Cross. From October 26 to 29 of that year, an international conference met in Geneva at the invitation of this small committee ${ }^{1}$. It passed a series of resolutions, the first of which determined the creation of a committee, in each country, to combine with the Army Medical Services in the event of war, and the eighth of which created the white armlet with the red cross superimposed. The Conference also expressed wishes which in the following year were the subject of the first Geneva Convention.

This Conference of 1863 saw the birth of the International Red Cross.

1 Plate. 


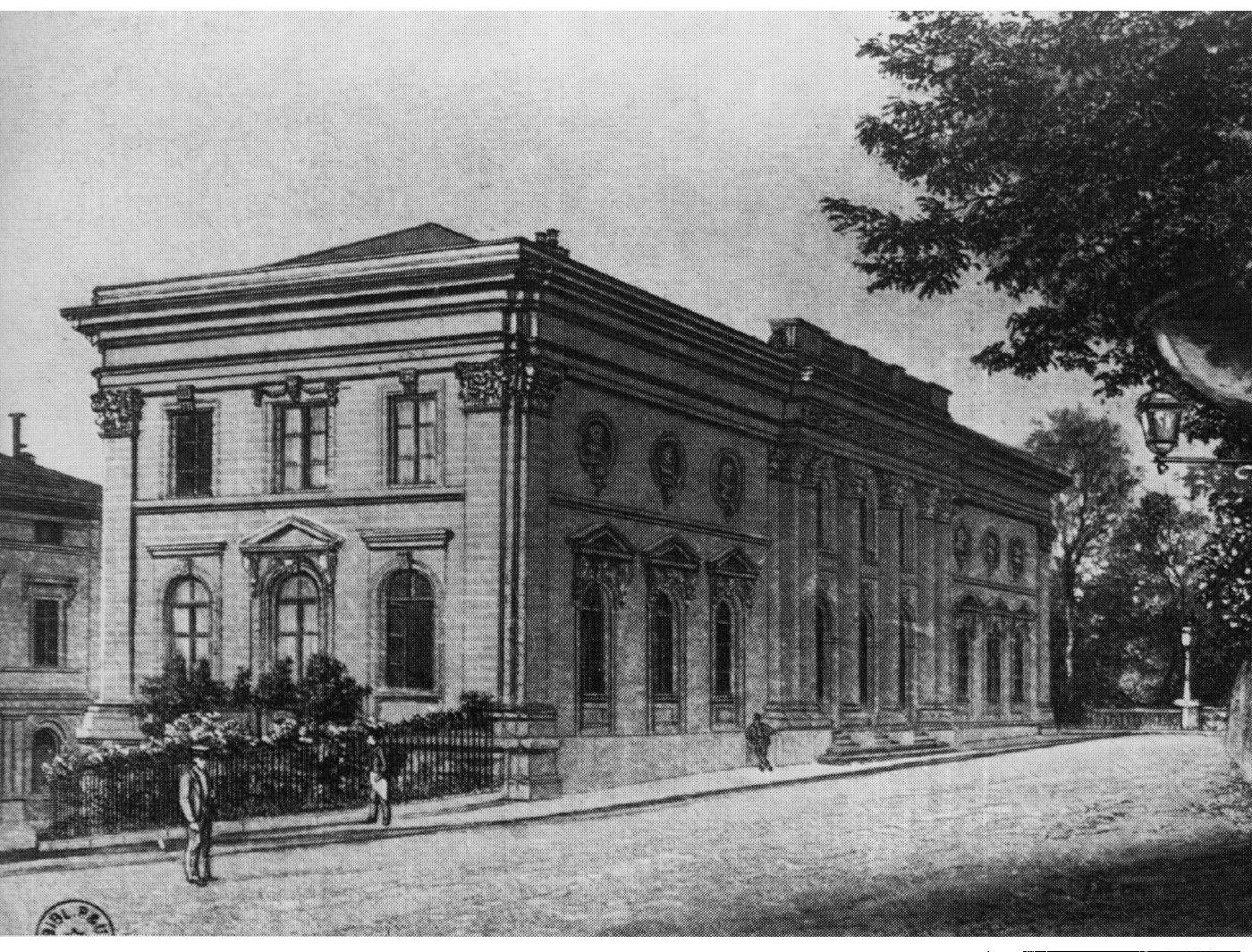

It was in Geneva, in a building called the Athené, that the Committee of Five welcomed the representatives of sixteen Furopean countries, in October I863. 


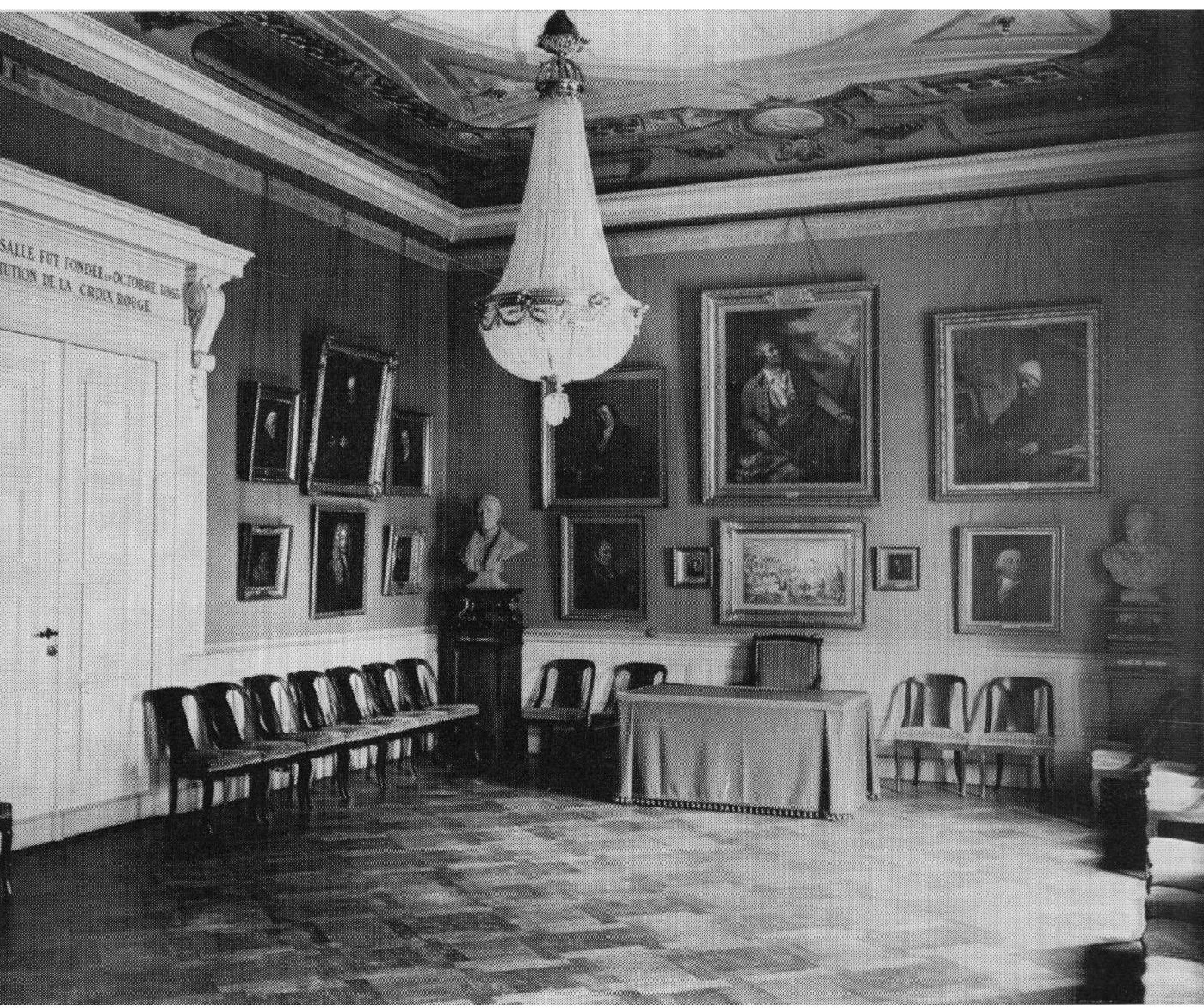

It was in this hall of the Athénée that the work of the Red Cross was begun a century ago. 
From this movement, modest and limited at the outset, has arisen one of the greatest universal institutions of our time. Over the last hundred years, most of the nations of the world have acceded to the Geneva Conventions and possess a National Red Cross, Red Crescent or Red Lion and Sun Society. Furthermore, the Red Cross which at the beginning was limited to sick and wounded military, has extended its care and protection by convention to other war victims (prisoners of war, civilian internees, civilian populations). The National Societies have extended their activities in peace time to victims of natural disasters, epidemics, lack of hygiene, all of which strike humanity as blindly as war. There is not one sector of human suffering in which the Red Cross cannot intervene either as an auxiliary to the public authorities or as a pioneer.

The entire world, therefore, is preparing to celebrate the Centenary of the foundation of the Red Cross this year. But it was fitting that this event should be the object of a special celebration in the country and the town in which the Red Cross saw the light of day, and in 1958, a meeting composed of representatives of the three Red Cross institutions with headquarters in Geneva - The International Committee of the Red Cross, The League of Red Cross Societies and the Swiss Red Cross-as well as representatives of the Federal Authorities, of the Canton and City of Geneva, decided to set up a special commission called the "Commission for the Red Cross Centenary in Switzerland ".

This Commission has prepared a programme, the general outline of which will be given later on. But it has, first of all, determined the general spirit in which the Centenary Ceremonies should be conceived. They must assume a solemnity worthy of the idea which they commemorate, be attractive enough for the public to take part and to live up to the expectations of the thousands of Red Cross "servants" from all over the world who will be coming to Geneva to the very source of the Red Cross. However, all frivolous or unnecessary celebrations must be avoided. The Red Cross must not be made the pretext for banqueting, even for a Centenary. Those who contribute to the Red Cross must not be allowed to think that their contributions are being squandered. Finally, these celebrations must have an educational character, help to give a better understanding of the significance and work of the Red Cross and attract to it increasing numbers of adherents. 
In 1963, the Red Cross must rediscover Henry Dunant's state of mind in his book. Although he described fully his activities and those of the women of Solferino on behalf of the wounded, it was never to boast or to attract compliments. It was to show the extent of the disaster, to make the reader realize the useless suffering of war. He explained what a few people of goodwill had been able to achieve, the better to deplore what it had not been possible to do. And he sought, in conclusion, the means which in the future would make relief more prompt, bigger, better organized and therefore more effective.

These are the same feelings with which the Red Cross must look back on its first century of activity. The gigantic development of this movement is worth stressing, but it must not be made the pretext for vain glory. The history of this development provides proof of the usefulness of the Red Cross and of the value of individual devotion of which it is the sum total. We can observe that at the present time, the spirit which animates it and the work which it carries out are more necessary than ever, but we must then be quite certain in the light of past experience, that we can do still better in the future and seek the means to do so.

In other words the Centenary Ceremonies must be not so much the conclusion of a glorious century, as the point of departure for still more fruitful years. The Celebrations organized in numerous countries by the National Red Cross, Red Crescent and Red Lion and Sun Societies, will take place in the same spirit, as a sign of fidelity to our common ideal and to mark its universality.

\section{FRÉDÉRIC SIORDET}

Vice-President of the International Committee of the Red Cross

Chairman of the Commission for the Red Cross Centenary in Switzerland 